\title{
Primary undifferentiated embryonal sarcoma of the liver mistaken for hydatid disease
}

\author{
Walid Faraj ${ }^{*}$, Deborah Mukherji ${ }^{2}$ Nadim El Majzoub², Ali Shamseddine², Achraf Shamseddine ${ }^{1}$, Mohamed Khalife ${ }^{1}$
}

\begin{abstract}
Primary undifferentiated embryonal sarcoma of the liver is a rare tumor with a peak incidence between the ages of 6 and 10 years. We report a case of a primary hepatic undifferentiated embryonal sarcoma arising in a 21-year-old male mistaken for hydatid disease of the liver. The rapid recurrence of this tumor along the site of attempted percutaneous drainage illustrates some important management points regarding this malignancy.
\end{abstract}

\section{Introduction}

Primary undifferentiated embryonal sarcoma (UES) of the liver is a rare and highly malignant neoplasm of mesenchymal origin. The majority of primary hepatic malignancies are carcinomas with primary hepatic sarcomas representing between $0.1 \%$ and $2 \%$ of primary hepatic cancers [1]. UES of the liver is most commonly seen arising in children with a peak incidence between 6 and 10 years but can arise in adults [2].

Our institution is a leading tertiary referral centre for the treatment of hepatic malignancies in the region. From 1998 to 2009, 215 adult patients were diagnosed with primary hepatic malignancies at our institution, 4 of which were diagnosed with primary hepatic sarcoma (1.8\%). Three cases were primary hepatic leiomyosarcomas (LMS) and one case was primary UES of the liver mistaken for hydatid disease in a 21-year-old male patient. Hydatid disease is endemic in the Middle East and is top of the differential diagnosis for a cystic liver lesion presenting in this age group.

\section{Case Report}

A 21 year old male patient was referred to our institution following unsuccessful surgery for presumed hydatid disease of the right lobe of the liver. The initial operation was performed in a district hospital; an open approach was performed and an attempt to drain/resect the lesion failed. The operation was aborted and a percutaneous drain was inserted at the site of surgery. The patient was in hospital for 2 weeks with no

\footnotetext{
* Correspondence: wfaraj@hotmail.com

'Department of Surgery, HPB and liver transplantation unit, American University of Beirut Medical Center, Beirut, Lebanon
}

improvement. The family decided to transfer him to our institution which is a tertiary care center specialized in hepatobiliary surgery.

On admission, the patient was in respiratory distress with severe abdominal pain, distension and lower limb edema. The alpha-fetoprotein (AFP) at the time of diagnosis was $3.6 \mathrm{U} / \mathrm{mL}$ (range 1-9), carcinoembryonic Ag (CEA) $2.2 \mathrm{ng} / \mathrm{mL}$ (range 0-4) and human chorionic gonadotropin (Beta- HCG) $3.6 \mathrm{mlU} / \mathrm{mL}(<=4)$. The laboratory tests included INR median 1.4 (range 0.91.1), serum bilirubin (Total) $1.4 \mathrm{mg} / \mathrm{dL}$ (range 0-1.2), serum aspartate aminotransferase (AST) $113 \mathrm{IU} / \mathrm{L}$ (range 0-50), gamma-glutamyl transferase $95 \mathrm{IU} / \mathrm{L}$ (range 0-50), creatinine $0.6 \mathrm{mg} / \mathrm{dL}$ (range 0.5-1.2), platelet count $680 \times 10^{9} / \mathrm{L}$ (range 150-400) and haemoglobin $11 \mathrm{~g} / \mathrm{dl}$ (range 13-18). ELISA test was negative for hydatid disease Serology was negative for hepatitis B, C and HIV.

A computed tomography (CT) scan of the abdomen revealed a large, well defined lesion with intracystic septations occupying the right hepatic lobe measuring $22 \times$ $19 \times 23.6 \mathrm{~cm}$ containing the percutaneous drain (Figure 1). Significant abdominal ascites was noted.

A technically challenging extended right hepatectomy was performed. Histopathology revealed an unusual neoplasm composed of irregular spindle cells showing moderate pleomorphism and brisk mitotic activity (Figure 2). Immunohistochemical studies showed positive staining for vimentin and a positive cytokeratin AE1/3. Diagnosis was made of a stage III undifferentiated embryonic sarcoma (UES). The patient was discharged home day 16 post-resection. Adjuvant chemotherapy was recommended and the patient elected to be treated in his 


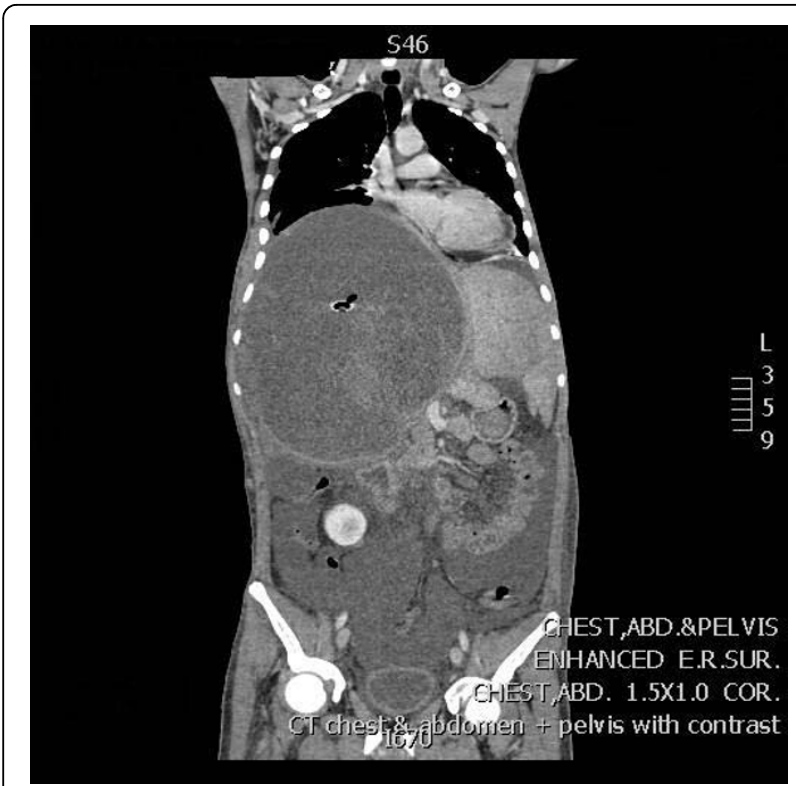

Figure $1 \mathrm{~A}$ computed tomography (CT) scan of the abdomen with a large lesion occupying the right hepatic lobe.

native country. Three weeks post-discharge he re-presented to our institution with a fungating abdominal wall mass at the site of previous percutaneous drain insertion. CT scan revealed a new lesion in segment II and an intra-abdominal lesion extending through the drain site $5 \mathrm{~cm}$ outside the skin (Figure 3 ). The skin lesion was resected and histopathological examination revealed metastatic UES. He elected to go back to his country of origin where he received adjuvant

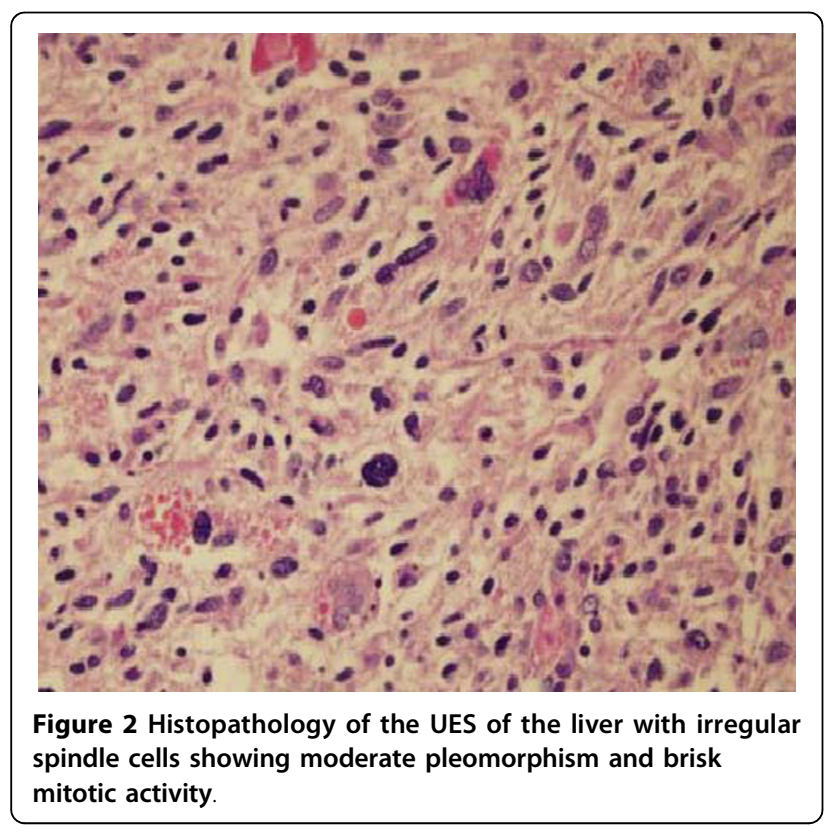

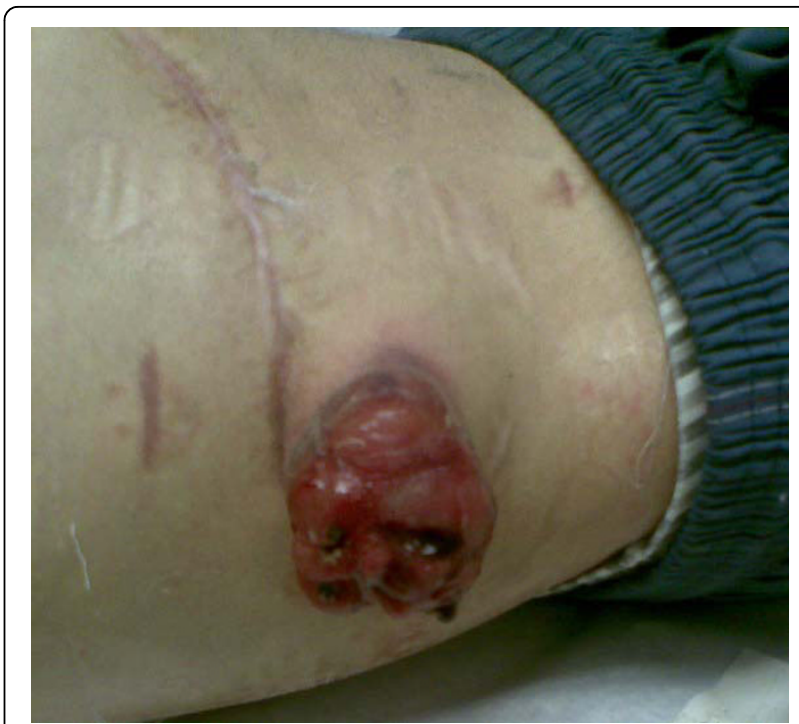

Figure 3 Intra-abdominal lesion extending through the drain site $5 \mathrm{~cm}$ outside the skin

chemotherapy which was ifosfamide plus etoposide alternating with actinomycin-D, vincristine every 3 weeks for 6 months. He is currently 5 months postresection and a recent $\mathrm{CT}$ scan showed no evidence of disease recurrence.

\section{Discussion}

Diagnosis of primary hepatic sarcoma is challenging due to the lack of specific presenting symptoms, lack of serological markers, non-specific findings on radiological imaging and the rarity of the disease. Pachera et al recently reviewed the literature on primary hepatic UES and found that in the past 50 years only 51 cases have been reported in patients older than 15 years [3]. UES often show a misleading cystic appearance on $\mathrm{CT}$ and magnetic resonance imaging (MRI) in contrast to a predominantly solid appearance on ultrasound [4]. This finding may help to avoid attempts at drainage as in the case we have presented. In their literature review, Pachera et al found that the diagnosis of UES was delayed in 12 cases $(23.5 \%)$ where the presentation with large cystic hepatic mass was suggestive of a benign lesion. There have been previous case reports of hepatic UES being mistaken for hydatid disease [5-8] however this is the first report of a case in which the diagnosis was made after attempted percutaneous drainage with evidence of rapid track-seeding and progression postresection.

Hydatid disease is a common pathology in our region and the surgical options are numerous. Surgeons may opt to remove the cysts through an open approach or laparoscopic approach. In either approach, it should be 
decided whether a radical path or a more conservative one should be taken. With regards to open surgery, several recent studies have shown that the radical approach is associated with lower rates of recurrence, fewer complications such as bile leak and decreased mortality. Percutaneous drainage of hydatid disease is another option, but we try to avoid this due to the risk of intra-abdominal spillage.

In our institution, both open and laparascopic procedures are performed and the choice of approach depends on the size and location of the hydatid lesion [9-11].

Complete resection followed by adjuvant chemotherapy is the current standard of care for hepatic UES, however due to the rarity of the disease, limited data exists and treatment remains largely empirical. Positive resection margins and spontaneous or iatrogenic rupture of the tumour are associated with early recurrence and death [3]. Lenze et al reviewed treatment outcomes for 68 patients over the age of 15 years and found a median survival of 29 months. Patients who underwent complete resection followed by adjuvant chemotherapy had significantly better survival compared with patients who underwent surgical resection alone. As expected, incomplete resection was associated with poorer outcome [12].

There have been three reports of liver transplantation for UES in children [13-15] however the use of liver transplantation for primary hepatic sarcoma in adults is controversial. There are no reports of liver transplantation for UES in adults and outcomes of liver transplantation for other histological subtypes such as hepatic angiosarcoma and LMS have been disappointing [16,17].

The case we have presented demonstrates the propensity of this tumour to rapidly recur along a percutaneous track however tumour control was achieved with a second radical resection followed by adjuvant chemotherapy.

\section{Conclusion}

In summary, this case illustrates some important aspects of this rare disease:

1. The discrepancy between CT and ultrasound appearances of this lesion is a key factor that should raise the index of suspicion when noted.

2. Due to the propensity of this lesion to seed along a percutaneous track, percutaneous biopsy or percutaneous drainage should not be attempted.

3. Complete resection must be attempted including resection of any potential percutaneous track followed by adjuvant chemotherapy.

4. If a percutaneous track cannot be resected, radiotherapy should be considered to reduce the risk of recurrence.

\section{Consent}

Written informed consent was obtained from the patient for publication of this case report and accompanying images. A copy of the written consent is available for review by the Editor-in-Chief of this journal.

\section{Author details}

'Department of Surgery, HPB and liver transplantation unit, American University of Beirut Medical Center, Beirut, Lebanon. ${ }^{2}$ Department of Internal medicine, Oncology unit, American University of Beirut Medical Center, Beirut, Lebanon.

\section{Authors' contributions}

WF drafted the manuscript, NEM and DM participated in the design of the study, ACS assisted with the collection of data and conceived of the study, MK and AIS participated in the design and coordination of the study. All authors read and approved the final manuscript.

\section{Competing interests}

The authors declare that they have no competing interests.

Received: 22 March 2010 Accepted: 9 July 2010 Published: 9 July 2010

\section{References}

1. Matthaei H, Krieg A, Schmelzle M, Boelke E, Poremba C, Rogiers X, Knoefel WT, Peiper M: Long-term survival after surgery for primary hepatic sarcoma in adults. Arch Surg 2009, 144(4):339-44.

2. Stocker JT, Ishak KG: Undifferentiated (embryonal) sarcoma of the liver: report of 31 cases. Cancer 1978, 42:336-348.

3. Pachera S, Nishio H, Takahashi Y, Yokoyama Y, Oda K, Ebata T, Igami T, Nagino M: Undifferentiated embryonal sarcoma of the liver: case report and literature survey. J Hepatobiliary Pancreat Surg 2008, 15:536-544.

4. Buetow PC, Buck JL, Pantongrag-Brown L, Marshall WH, Ros PR, Levine MS, Goodman ZD: Undifferentiated embryonal sarcoma of the liver: pathological basis of imaging findings in 28 cases. Radiology 1997, 203:779-783.

5. Charfi S, Ayadi L, Toumi N, Frikha F, Daoud E, Makni S, Frikha M, Beyrouti Ml, Sellami-Boudawara T: Cystic undifferentiated sarcoma of liver in children: a pitfall diagnosis in endemic hydatidosis areas. J Pediatr Surg 2008, 43:E1-4

6. Aggarwal S, Guleria S, Dinda AK, Kumar L, Tarique S: Embryonal sarcoma of the liver mimicking hydatid cyst in an adult. Trop Gastroenterol 2001, 22:141-142.

7. Joshi SW, Merchant NH, Jambhekar NA: Primary multilocular cystic undifferentiated (embryonal) sarcoma of the liver in childhood resembling hydatid cyst of the liver. Br J Radiol 1997, 70:314-316.

8. Zaheer W, Allen SL, Ali SZ, Kahn E, Teichberg S: Primary multicystic embryonal sarcoma of the liver in an adult presenting with peripheral eosinophila. Ann Clin Lb Sci 1994, 24:495-500.

9. De Werra C, Condurro S, Tramontano S, Perone M, Donzelli I, Di Lauro S, Di Giuseppe M, Di Micco R, Pascariello A, Pastore A, Diamantis G, Galloro G: Hydatid disease of the liver: thirty years of surgical experience. Chir Ital 2007, 59:611-625.

10. Priego P, Nuño J, López Hervás P, López Buenadicha A, Peromingo R, Díe J, Rodríguez G: Hepatic hydatidosis. Radical vs. conservative surgery: 22 years of experience. Rev Esp Enferm Dig 2008, 100:82-85

11. Sayek I, Tirnaksiz MB, Dogan R: Cystic hydatid disease: current trends in diagnosis and management. Surg Today 2004, 34:987-996.

12. Lenze F, Birkfellner T, Lenz P, Hussein K, L228;nger F, Kreipe $H$, Domschke W: Undifferentiated embryonal sarcoma of the liver in adults. Cancer 2008, 112L:2274-2282.

13. Kelly MJ, Martin L, Alonso M, Altura RA: Liver transplantation for relapsed undifferentiated embryonal sarcoma in a young child. J Pediatr Surg 2009, 44:E1-E3.

14. Dower NA, Smith $\sqcup$ : Liver transplantation for malignant liver tumors in children. Med Pediatr Oncol 2000, 34:1320135.

15. Okajima H, Ohya Y, Lee KJ, Yamamoto H, Asonuma K, Nagaoki Y, Ohama K, Korogi M, Anan T, Hashiyama M, Endo F, lyama K, Inomata $Y$ : Management 
of undifferentiated sarcoma of the liver including living donor liver transplantation as a backup procedure. J Pediatr Surg 2009, 44:E33-E38.

16. Husted TL, Neff G, Thomas MJ, Gross TG, Woodle ES, Buell JF: Liver transplantation for primary or metastatic sarcoma to the liver. Am J Transpl 2006, 6:392-397.

17. Liang X, Xiao-Min S, Jiang-Ping X, Jie-Yu Y, Xiao-Jun Z, Zhi-Ren F, GuoShan $D$, Rui-Dong L: Liver transplantation for primary hepatic leiomyosarcoma: case report and review of literature. Med Oncol 2009, DOI 10.1007/s12032-009-9372-z

doi:10.1186/1477-7819-8-58

Cite this article as: Faraj et al.: Primary undifferentiated embryonal sarcoma of the liver mistaken for hydatid disease. World Journal of Surgical Oncology 2010 8:58.

Submit your next manuscript to BioMed Central and take full advantage of:

- Convenient online submission

- Thorough peer review

- No space constraints or color figure charges

- Immediate publication on acceptance

- Inclusion in PubMed, CAS, Scopus and Google Scholar

- Research which is freely available for redistribution

Submit your manuscript at www.biomedcentral.com/submit 